\title{
Welding Deformation of Hydraulic Support Measurements by Using FBG Sensors
}

\author{
Shangyu Du $\mathbb{D}^{1,2,3}$ Guofa Wang, ${ }^{1,2}$ Yajun $\mathrm{Xu}^{2,3}$ Ying Ma, ${ }^{2,3}$ Desheng Zhang, ${ }^{2,3}$ Qiang Ma, ${ }^{1}$ \\ and Xingtong Yue ${ }^{4}$ \\ ${ }^{1}$ CCTEG Coal Research Institute, Beijing 100013, China \\ ${ }^{2}$ Tiandi Science and Technology Co., Ltd., Beijing 100013, China \\ ${ }^{3}$ CCTEG Coal Mining Research Institute, Beijing 100013, China \\ ${ }^{4}$ Ansteel Beijing Research Institute Co., Ltd., Beijing 102209, China
}

Correspondence should be addressed to Shangyu Du; dusy6509@163.com

Received 15 July 2021; Accepted 30 July 2021; Published 4 August 2021

Academic Editor: Dezhong Kong

Copyright ( $\odot 2021$ Shangyu Du et al. This is an open access article distributed under the Creative Commons Attribution License, which permits unrestricted use, distribution, and reproduction in any medium, provided the original work is properly cited.

The welding deformation and cracking of hydraulic support have always been an important issue that impacts product quality and performance in the industry. In order to quantify the deformation of the welding seam of the reverse four-bar linkage hydraulic support under loading conditions, a real-time weld monitoring system based on sensitive fiber Bragg grating sensors is designed. The strength test and the cycle life test of the top coal caving reverse four-link support with four typical eccentric loads were conducted, respectively. The strength test results prove that the fiber Bragg grating sensor is accurate enough to measure welding deformation of hydraulic support; the measurement resolution reaches $0.1 \mu \mathrm{m}$. The eccentric load experiment produces the reverse four-bar torsion, especially when the top beam is at a low position; the maximum deformation of the weld is $100 \mu \mathrm{m}$. In the cycle test, a phenomenon has been captured, i.e., the welds present a baseline shift along with the cyclic load and even jump. It indicates that the hydraulic support changes from one stable state to another stable state. This work not only provides a feasible solution for welding deformation monitoring but also provides a possibility for the whole life cycle monitoring of hydraulic supports.

\section{Introduction}

According to the latest World Energy Data Statistics Report for 2019 provided by the British company BP, the total annual global power generation in 2019 was 27004.7 TWh. Among the fossil energy used for power generation in the world, coal supports $30 \%$ of the total global power generation, which is still an important part of the world's energy. At present, the underground coal mines are mainly mined in the form of comprehensive mechanized coal mining, using highly automated "three fully mechanized mining machines," namely, shearer, scraper conveyors, and hydraulic supports [1]. The hydraulic support plays a vital role in supporting the roof of the coal mining face and protecting the equipment and workers of the coal mining face [2].
The top coal transition support is one of the most important support equipment for comprehensive mechanized top coal mining. Its performance and quality directly determine the output and efficiency of the fully mechanized caving face [3]. The mechanical characteristics of the reverse four-bar linkage mechanism of the transition support are better than those of the positive four-bar linkage transition support, and it is more suitable for top coal mining. However, most of the top coal mining is faced with unfavourable situations such as large thickness drop and complex geological conditions, making it difficult for traditional simulation to obtain force characteristics close to the actual application. According to the actual application of the reverse four-bar linkage structure of the top coal caving transition support underground, the weld seam of the four-bar linkage structure 
often deforms or even cracks, which poses a serious threat to underground safety production.

The requirements for hydraulic support consist of rational structure, sufficient support resistance force, stable and shock resistance, the sustainability of highly efficient coal discharge, and high coal recovery $[4,5]$. Zhao et al. analysed the structural characteristics of hydraulic supports with box-type structures based on simulation, whose results show structural stress concentration is the main factor leading to the fatigue damage of hydraulic supports [6]. Liu and Junqing Liu analyse structured statics and transient dynamics of the hydraulic support strength test under base torsion by ANSYS software [7]. Fu Fang et al. compared using automatic TANDEM twin-wire welding and twin-wire gas metal welding (GMAW) to weld Q690 steel, and pointed that TANDEM twin-wire welding is very suitable in the welding of Q690 used in the hydraulic support [8].

Welding deformation and cracking of hydraulic support structural parts have always been an important issue that impacts product quality and performance in the industry. The shutdown of the working face caused by structural cracking is an important reason for users' dissatisfaction with product performance [9]. The hydraulic support structure belongs to a multichamber box girder structure composed of plates and profiles. The number of welds is densely arranged; the size of the welds is large; the structural stress concentration is serious, and the residual stress distribution is complex, which lead to hydraulic support working in an unstable state $[9,10]$, especially for the top coal caving transition hydraulic support with reverse fourlink structure. In the actual work of the reverse four-link structure, the welding seam stretching and even cracking caused by the unbalanced top and floor pressure cannot be calculated by simulation. Due to the complicated wiring, traditional resistive strain sensors are not suitable for longterm monitoring underground, especially in humid environments.

With the development of sensing technology, researchers begin to use modern sensing technology to measure the pressure, stress distribution, posture, and deformation of hydraulic supports in actual work [11-13]. For instance, the displacement sensor and pressure sensor are equipped with modern hydraulic support to quantify the working resistance [14]; a fiber Bragg grating (FBG) tilt sensor based on double equal strength beams is designed and used to monitor the posture of hydraulic supports [15]; Zhen and $\mathrm{Ma}$ et al. reported optical FBG sensors for aircraft wing shape measurement [16]. Optical fiber sensing technology is a sensing technology that uses light propagation path as a medium to sense external strain [17], magnetic field [18], temperature [19], vibration [20], and other information. Because of its passive, anti-interference, anticorrosion, and small size, it has been widely used in important fields such as petrochemical [21], aerospace [22], biomedicine [23], national defense and military [24], and environmental monitoring [25].

To reveal the deformation of the welding seam of the reverse four-bar linkage hydraulic support under loading conditions, in this paper, we adopted an FBG sensor to measure the deformation of the weld of the reverse four-bar linkage. Furthermore, we designed a real-time weld monitoring system, based on a fiber optic demodulator with sensitive FBG sensors and a NI DAQ-6002 board, which is used to sample the pressure of hydraulic support. They were synchronized by the inner timer of the host computer.

To quantify the relationship between the welding deformation and the pressure of the load under different working conditions, the strength test and the cycle life test of the top coal caving reverse four-link support with four typical eccentric load were conducted, respectively. The results of strength test show that the eccentric load experiment produces the reverse four-bar torsion; the maximum deformation of the weld reaches $100 \mu \mathrm{m}$. In the cycle test, we found that the welding deformation presents a baseline shift along with the cyclic load, and even jumps.

\section{Materials and Methods}

2.1. Fiber Bragg Grating Sensor. In 1978, Canadian physicist Ken Hill demonstrated the grating effect for the first time [26]. The principle of fiber grating is shown in Figure 1. An intense ultraviolet laser is used in "writing" systematic variation of refractive index into the core of the special optical fiber. The Bragg gratings can be realized using microfabrication methods which can create refractive index modulation along the beam propagation direction. Besides the FBGs based on refractive index modulation, they can be also realized using heterocore fiber structures, taper structures, cladding removal, microbending structure, and macrobending structure [27]. Then, a broadband laser light source is used to transmit a broadband spectrum along a section of the fiber. $\Lambda_{\mathrm{a}}$ is the constant nominal period of refractive index modulation; after the light passes through the FBG, a certain bandwidth $\lambda_{\mathrm{a}}$ corresponding to $\Lambda_{\mathrm{a}}$ is reflected. The rest of the light continues propagating forward, the reflected light is separated from the incident light by the optical coupler, and then the light sensor is used to monitor the reflected light. When the FBG is squeezed or stretched by stress or temperature, the frequency of the reflected light will shift left to be $\lambda_{\mathrm{b}}$ or shift right to be $\lambda_{\mathrm{c}}$. Thus, FBG can be used as a sensor to sense temperature and strain.

2.2. Deformation Sensor with FBG. In our measurement, a sensitive sensor, Osc3110, made by Macron Optics company is adopted. The Osc3110 Strain Gage is shown in Figure 2, which is a spot-welded steel using a capacitive-discharge spot welder. The length of the optical strain gate is $2.38 \mathrm{~cm}$ and the spot weldable areas are arranged at both ends of the gate. Osc3110 is connected with a fiber demodulator by the optical fiber. Although osc3110 is a strain sensor, its structure is suitable for measuring the deformation. Due to the uniformly forced among the optical strain gate, it is reasonable to quantify the deformation of the welds on the hydraulic support.

Specifically, we utilize the parameters of the sensors to explain how we quantify the welding deformation by 


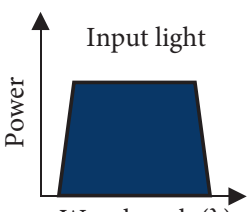

Wavelength $(\lambda)$
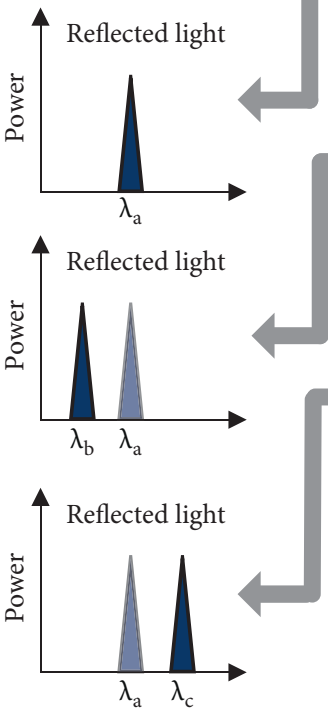
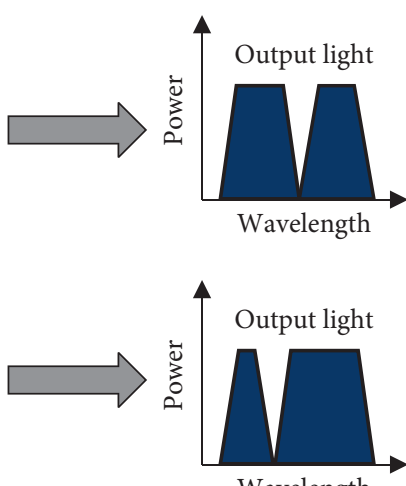

Wavelength

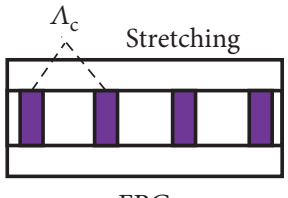

FBG

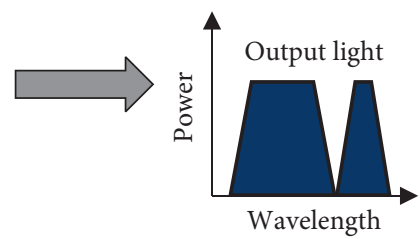

Figure 1: FBG principle.

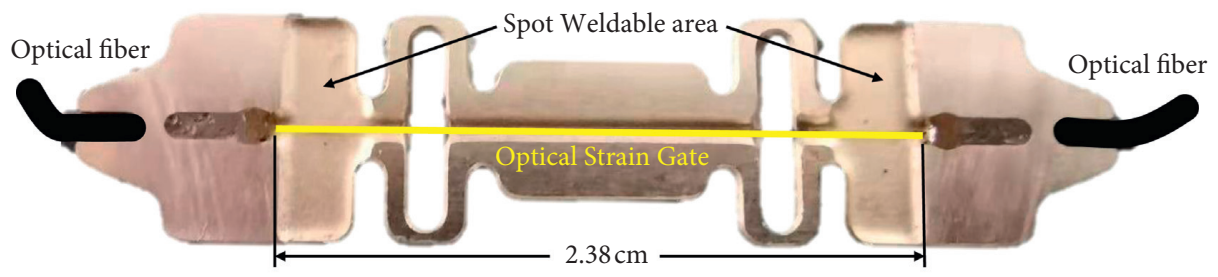

FiguRE 2: Deformation sensor.

Osc3110. According to the sensors' datasheets, we obtain the parameters of the five sensors shown in Table 1, where FG is gate factor, $\lambda_{0}$ is the nominal wavelength, $C_{1}$ is gate constant 1 , and $C_{2}$ is gate constant 2 .

Equation (1) introduces the relationship between the strain $\mathcal{E}$ and wavelength shift $\Delta \lambda$; here $\varepsilon_{\mathrm{TO}}$ indicates thermally induced apparent strain. The FBGs, which are based on the strain gages, respond to both strain and temperature. Thus, $\varepsilon_{\mathrm{TO}}$, shown in equation (2), is used to express how the temperature affects the strain measurement, where $\Delta T$ is the temperature change and $\mathrm{CTE}_{\mathrm{S}}$ is $13.3 \mathrm{ppm} /{ }^{\circ} \mathrm{C}$.

$$
\begin{aligned}
\varepsilon & =\frac{\left(\Delta \lambda / \lambda_{0}\right) \times 10^{6}}{F_{G}-\varepsilon_{\mathrm{TO}}}, \\
\varepsilon_{\mathrm{TO}} & =\Delta T\left[\frac{C_{1}}{F_{G}}+\mathrm{CTE}_{S}-C_{2}\right] .
\end{aligned}
$$

The temperature of the laboratory remains $12^{\circ} \mathrm{C}$, leading to $\Delta T$ as $10^{\circ} \mathrm{C}$. Substituting the values of Table 1 into equation (2), we get $\varepsilon_{\mathrm{TO}}$ as $62.17 \mu \mathrm{m}$. Although $\varepsilon_{\mathrm{TO}}$ represents a large number, the temperature of the laboratory can be viewed as constant; then $\varepsilon_{\mathrm{TO}}$ is subtracted as a zero bias.

To measure the deformation of the weld, we need to transform strain into deformation. Here, the length of the optical strain gate $L$ is $2.38 \mathrm{~cm}$ with a reasonable approximation that the optical strain gate is uniformly stressed; then we can get the expression of deformation $d$ as follows:

$$
d=\varepsilon \times L .
$$

So far, we have elaborated on the principle of measuring weld seams with FBG sensors.

2.3. Setup. In our experiments, we use a reverse four-bar transition support ZFG10000/23/38 for top coal caving as the research object. We chose several welds that often cracked when the reverse four-bar linkage is used in underground applications. In order to clearly show the sensor installation location, a 3D model of the support and the layout of measuring points are shown in Figure 3. To study 
TABle 1: Parameters of Osc3110.

\begin{tabular}{lcccc}
\hline Sensors & $F_{\mathrm{G}}$ & $\lambda_{0}$ & $C_{1}$ \\
\hline FBG1 & 0.89 at $22^{\circ} \mathrm{C}$ & $1550.83 \mathrm{~nm}$ at $22^{\circ} \mathrm{C}$ & $6.156 \mu \mathrm{m} / \mathrm{m}$ at $22^{\circ} \mathrm{C}$ & $0.7 \mu \mathrm{m} / \mathrm{m}$ \\
FBG2 & 0.89 at $22^{\circ} \mathrm{C}$ & $1552.58 \mathrm{~nm}$ at $22^{\circ} \mathrm{C}$ & $6.156 \mu \mathrm{m} / \mathrm{m}$ at $22^{\circ} \mathrm{C}$ & $0.7 \mu \mathrm{m} / \mathrm{m}$ \\
FBG3 & 0.89 at $22^{\circ} \mathrm{C}$ & $1549.75 \mathrm{~nm}$ at $22^{\circ} \mathrm{C}$ & $6.156 \mu \mathrm{m} / \mathrm{m}$ at $22^{\circ} \mathrm{C}$ & $0.7 \mu \mathrm{m} / \mathrm{m}$ \\
FBG4 & 0.89 at $22^{\circ} \mathrm{C}$ & $1558.70 \mathrm{~nm}$ at $22^{\circ} \mathrm{C}$ & $6.156 \mu \mathrm{m} / \mathrm{m}$ at $22^{\circ} \mathrm{C}$ & $0.7 \mu \mathrm{m} / \mathrm{m}$ \\
FBG5 & 0.89 at $22^{\circ} \mathrm{C}$ & $1556.80 \mathrm{~nm}$ at $25^{\circ} \mathrm{C}$ & $6.156 \mu \mathrm{m} / \mathrm{m}$ at $22^{\circ} \mathrm{C}$ & $0.7 \mu \mathrm{m} / \mathrm{m}$ \\
\hline
\end{tabular}

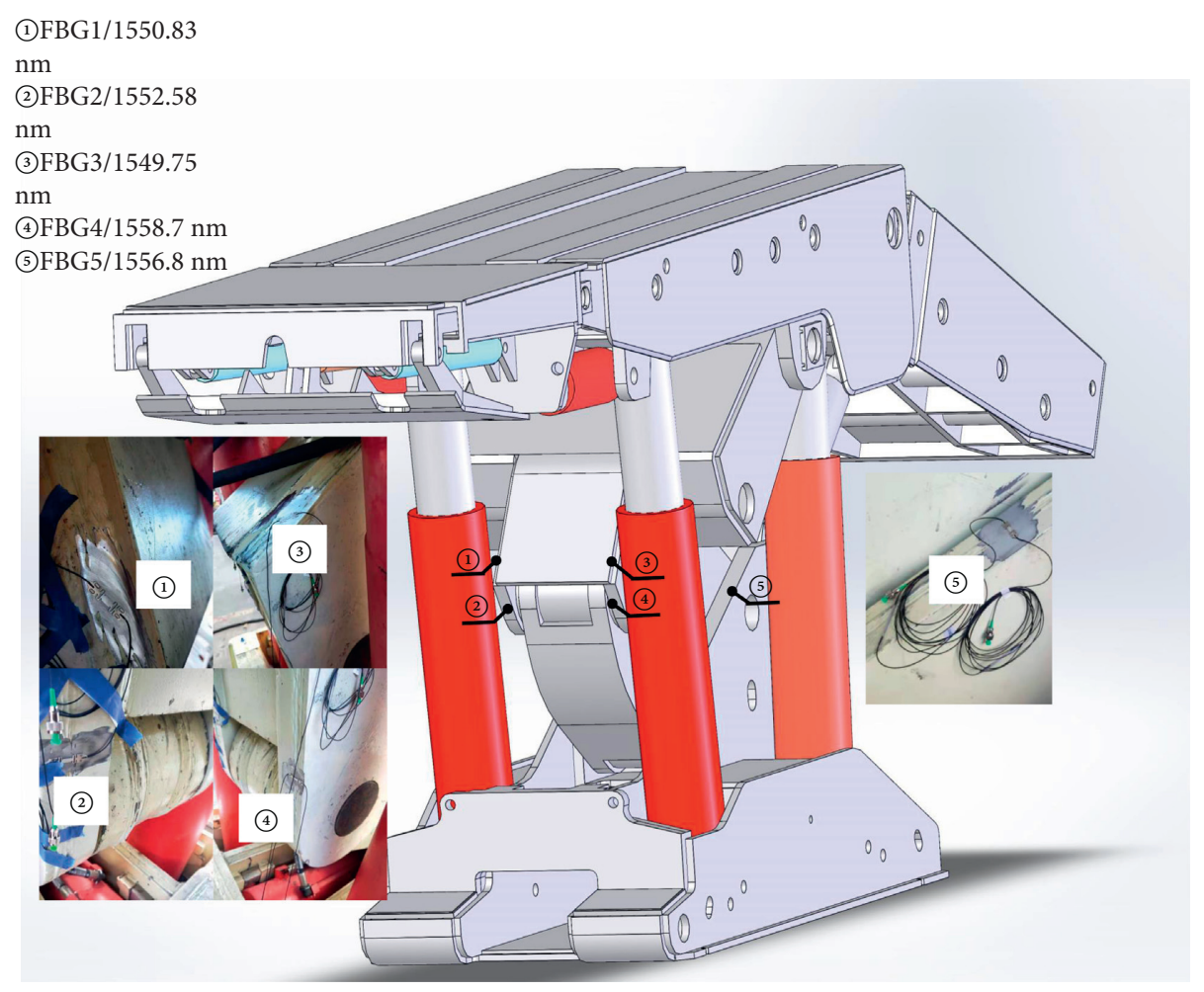

FIGURE 3: The layout of measuring points and 3D model of ZFG10000/23/38.

the deformation of the key welds of the reverse four-bar linkage under eccentric load experimental conditions, 5 FBG sensors are spot-welded cross the welds and their initial wavelengths are shown in the upper left corner of Figure 3.

To reveal how the deformation of the weld on the fourbar linkage changes with the loading pressure in the eccentric load experiment, a synchronized measurement system for hydraulic pressure and welding seam (Figure 4) was designed. The measurement system contains a hydraulic pressure measurement unit and an optical fiber data acquisition unit, and they are synchronized by the timestamp of the host computer. In the hydraulic pressure measurement unit, a pressure sensor with the precision of $0.5 \%$ F.S and the range of $0-60 \mathrm{MPa}$ is adopted; then NI DAQ-USB6002 is programmed to capture the hydraulic pressure data with sample rate $1 \mathrm{kHz}$. In the optical fiber data acquisition unit, we use optical strain gate Osc3120 series as our sensors as well as an optical spectrum analyser, operated by the MOI-ENLIGHT software on the host computer, to capture optical fiber signal. The optical spectrum analyser is an SM125-500 FBG static demodulator (produced by Micron
Optics, Inc., USA). Its main technical parameters are as follows: the wavelength scanning ranges from $1510 \mathrm{~nm}$ to $1590 \mathrm{~nm}$, scanning frequency is $2 \mathrm{~Hz}$, the wavelength resolution is $1 \mathrm{pm}$, and the sample rate is $1 \mathrm{kHz}$.

In the series of loading tests on the main structural parts of the hydraulic support, the high and low top beam eccentric loading test has the most severe test on the reverse four-bar weld. Here, we conduct four sets of trials: (1) left side eccentric loading of the top beam at the low position; (2) right side eccentric loading of the top beam at the low position; (3) left side eccentric loading of the top beam at the high position; (4) right side eccentric loading of the top beam at the high position. The loading diagram and block location are shown in Figure 5.

\section{Results}

3.1. Hydraulic Pressure Measurement. The measurements in our research are performed in the test bench of Safety Access Analysis and Verification Laboratory for Mine Support Equipment. The test bench applies pressure to the hydraulic 


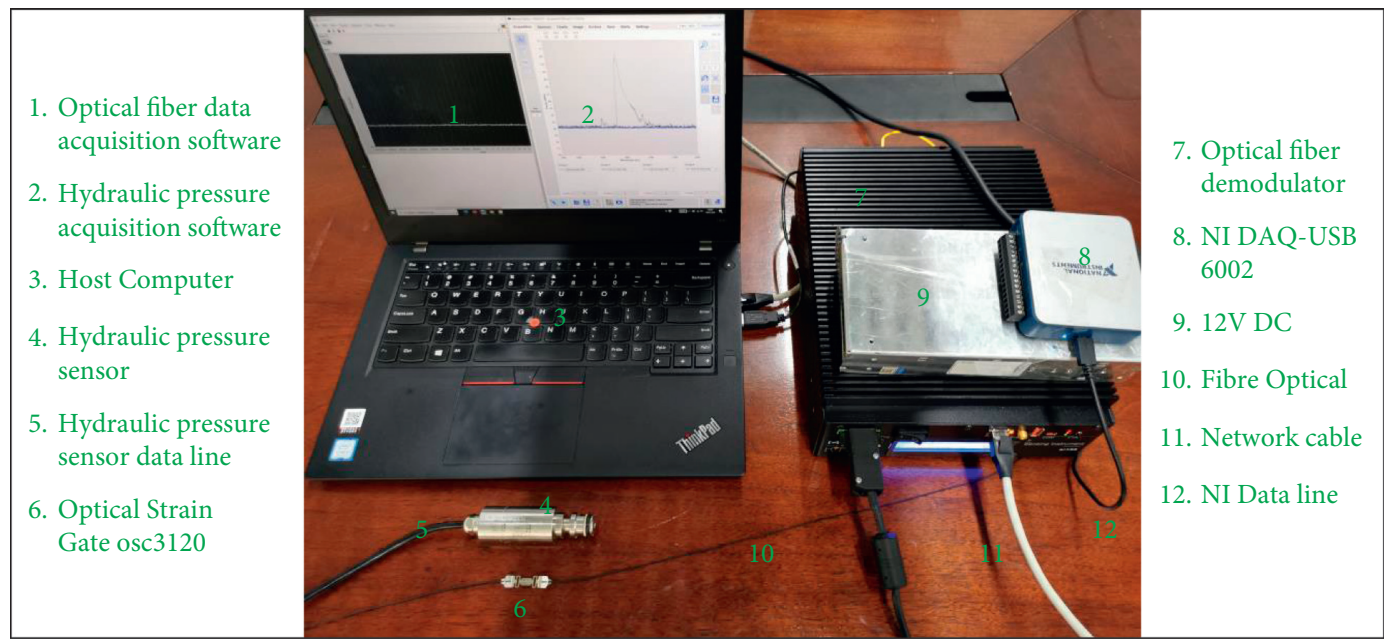

Figure 4: The synchronized measurement system for hydraulic pressure and welding seam.

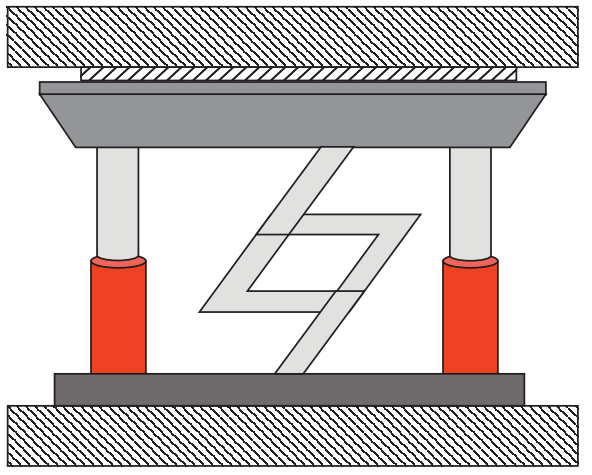

(a)

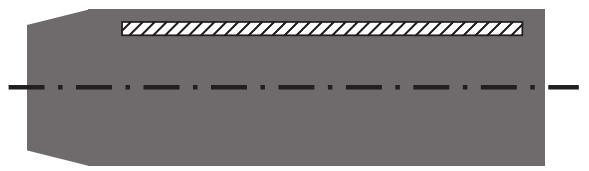

(c)

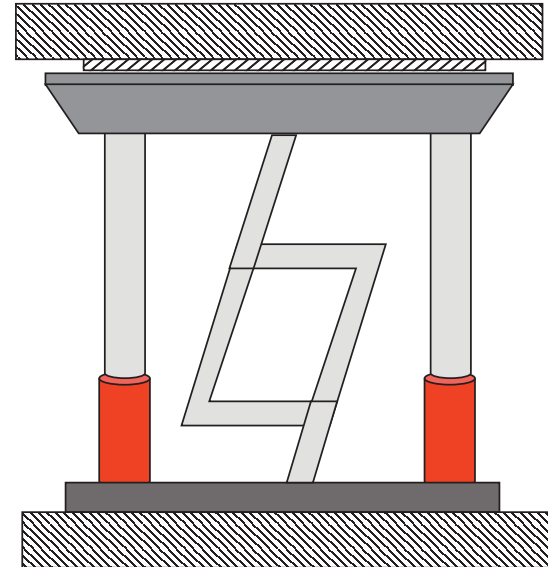

(b)

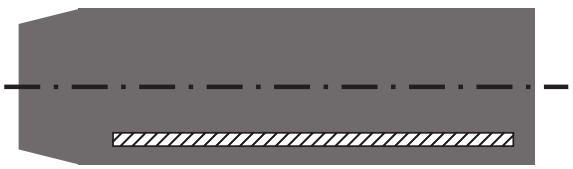

(d)

Figure 5: Loading diagram and block position. (a) Top beam at the low position. (b) Top beam at the high position. (c) The block at the left side of the top beam. (d) The block at the right side of the top beam.

support and the pressure sensor is connected to the hydraulic support through a three-way valve. Two top beam eccentric loading experiments, i.e., top beam at the high position and low position, are performed, respectively. And the hydraulic pressure is recorded (shown in Figure 6) by the synchronized measurement system which is introduced in Figure 4. The hydraulic pressure waveform in Figure 6(a) is used for the cycle life test of hydraulic support when its top beam is at a high position. From Figure 6(a), we can tell that the period of the waveform is $10 \mathrm{~s}$, and the hydraulic pressure starts approximately at $31 \mathrm{MPa}$ and then increases to $43.7 \mathrm{MPa}$ and keeps at $2 \mathrm{~s}$, dropping to $31 \mathrm{Mpa}$ eventually. Besides, in Figure 6(b), the hydraulic pressure varies from
$23 \mathrm{MPa}$ to $34 \mathrm{MPa}$, which is used for the cycle life test of the top beam at a low position.

3.2. Welding Deformation of Eccentric Loading with the Top Beam at a High Position. We have already detailed the measuring principle of weld deformation above. To study the deformation of the five welds with pressure loading, we trace the whole process of pressure loading; i.e., (1) hydraulic pressure stays zero; (2) hydraulic pressure increases slowly to $31 \mathrm{MPa}$; (3) hydraulic pressure varies periodically between $31 \mathrm{MPa}$ and $43.7 \mathrm{MPa}$ as shown in Figure 6(a). From Figure 7 , we can tell that the five deformations of weld start 


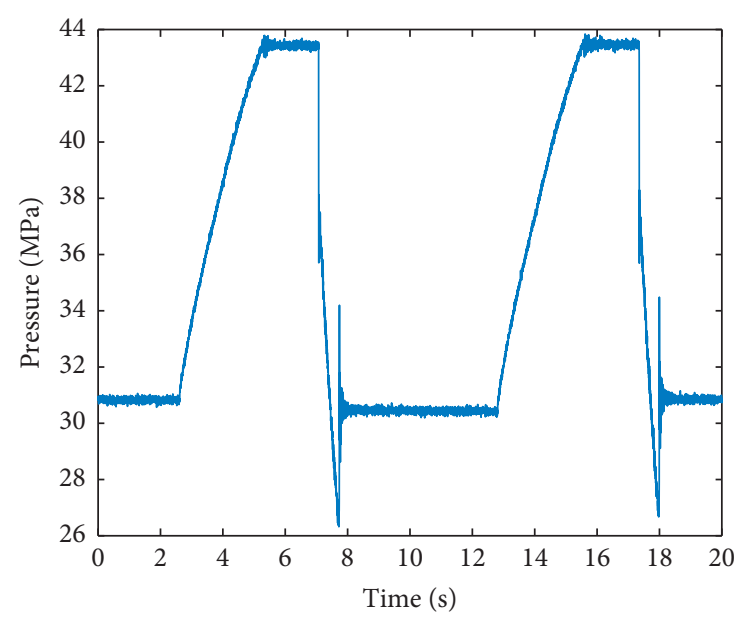

(a)

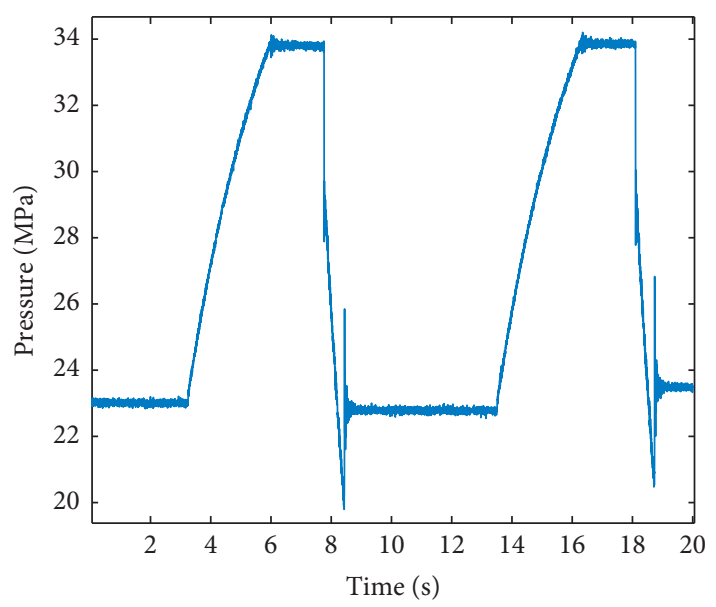

(b)

Figure 6: Hydraulic pressure waveform. (a) Top beam at the high position. (b) Top beam at the low position.

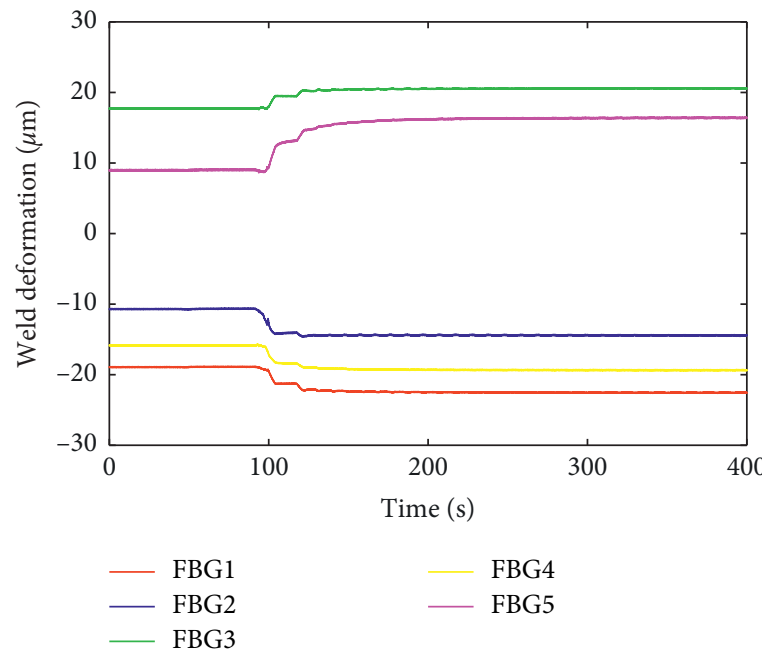

(a)

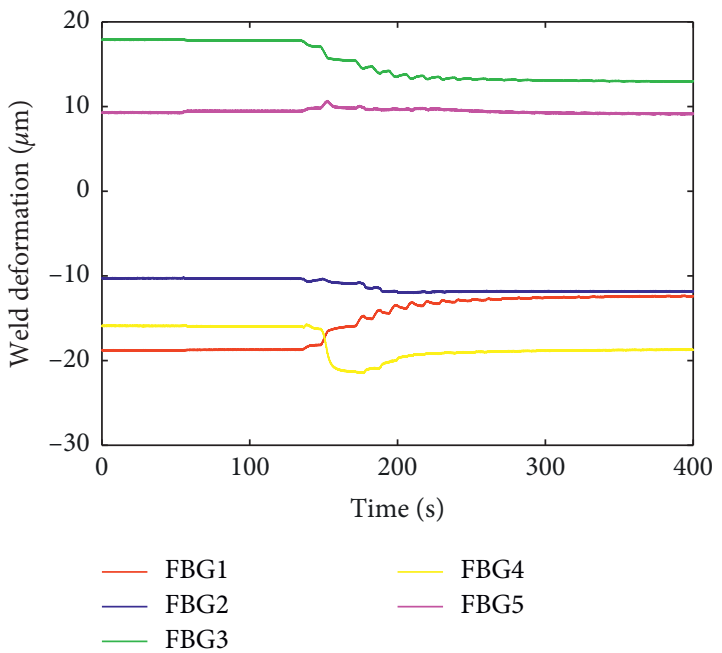

(b)

Figure 7: Welding deformation of eccentric loading of the top beam at a high position. (a) The block on the left side. (b) The block on the right side.

from different values, which is caused by the stress change during the hydraulic support being transported to the test bench; here, zero shift caused by temperature has been erased. Figure 7(a) illustrates five weld deformations of eccentric loading of the top beam at a high position when the block sets on the left side; it can be seen that FBG 3 and 5 increase at the positive phase; on the contrary, FBG 1,2, and 4 decrease at the negative phase, which means welds 3 and 5 are stretched and welds 1,2, and 4 are squeezed when the test bench provided hydraulic pressure. However, the condition is different in Figure 7(b); even though the initial welding deformation values of the five FBGs are the same as the ones shown in Figure 7(a), when the block sets on the right side, weld 1 is stretched, welds 1,2 , and 4 are all squeezed, and weld 5 approximately remains stable.
According to these two sets of experimental data, the force of the reverse four-bar linkage is even and symmetrical when the top beam is at a high position, and the stretch and squeeze amount of the weld is within $20 \mu \mathrm{m}$. Therefore, the fiber grating sensor is effective for measuring the change of the reverse four-bar weld; furthermore, it can be used to evaluate the pros and cons of the reverse four-bar linkage structure design.

3.3. Welding Deformation of Eccentric Loading with the Top Beam at a Low Position. We repeat the same measurements after the top beam was dropped to a low position. The hydraulic pressure increases slowly to $23 \mathrm{MPa}$ and then varies periodically between $23 \mathrm{MPa}$ and $34 \mathrm{MPa}$ as shown in 


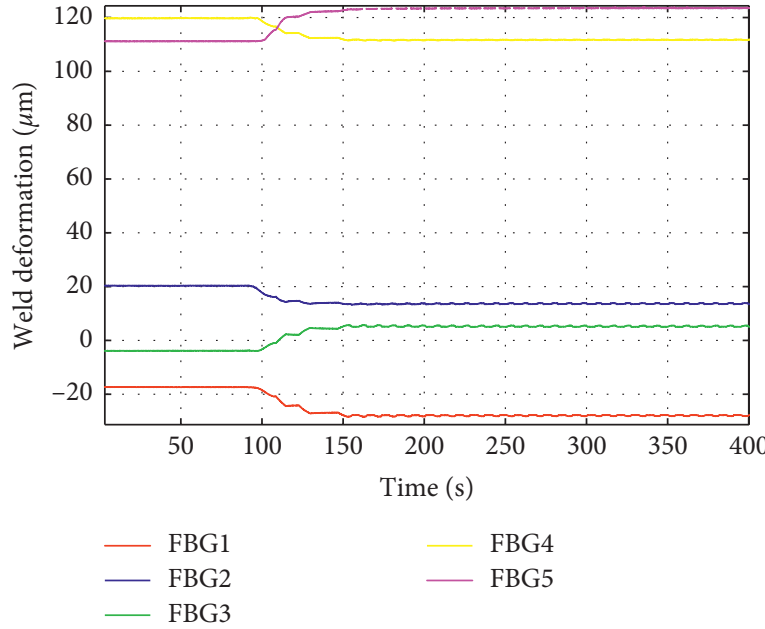

(a)

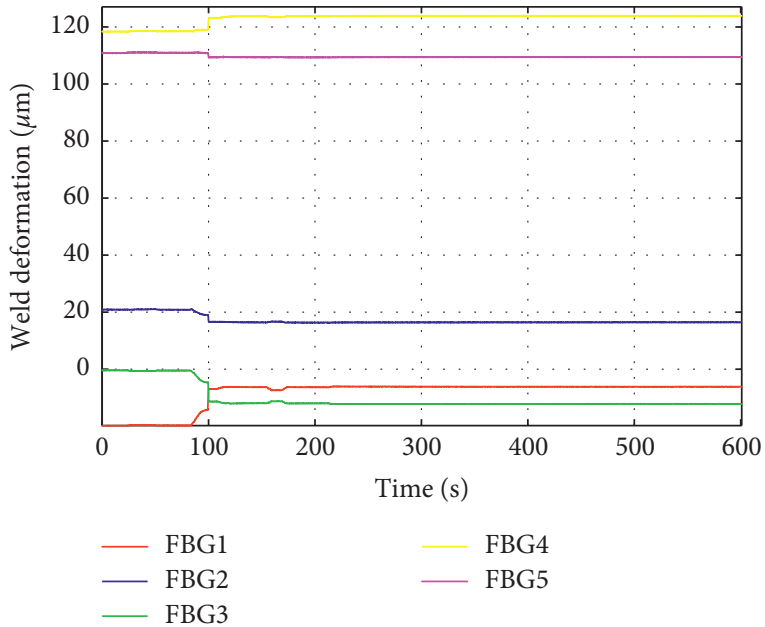

(b)

Figure 8: Welding deformation of eccentric loading of the top beam at a low position. (a) The block on the left side. (b) The block on the right side.

Figure 6(b). In Figure 8, the initial values of the five welding deformations are different from those in Figure 6, especially for FBG 4 and 5, whose welding deformations are stretched to $120 \mu \mathrm{m}$ and $110 \mu \mathrm{m}$, respectively. Compared with the weld change caused by the loading experiment, the one caused by the position of the top beam produces a greater weld deformation.

Figure 8(a) shows five welding deformations of eccentric loading of the top beam at a low position when the block sets on the left side. FBG 3 and 5 increase at the positive phase; on the contrary, FBG 1, 2, and 4 decrease at the negative phase, obeying the same principle revealed in Figure 7(a). However, in Figure 8(b), when the block sets on the right side, welds 1 and 4 are stretched and welds 2, 3, and 5 are all squeezed, which is different from that in Figure 7(b).

From the results, we can tell that, in the high and low loading test of the reverse four-bar linkage, the force law is not the same, especially when the block sets on the right side. We can also see some signs in the initial state of the low-position loading test that the weld deformation of FBG 4 and 5 is much larger than others, which means the hydraulic support is not in a stable state and could not be found by workers as usual. Thus, we can tell that FBG sensors can identify whether the hydraulic support is stable or not.

\subsection{Cycle Loading Test with the Top Beam at a Low Position.} To view the welding deformation under cycle loading test with the top beam at a low position, we erased the initials of the five welding deformations. As the hydraulic pressure is a waveform with a period of $10 \mathrm{~s}$, the weld deformations present the same characteristics, especially for FBG 1,2, and 3 shown in Figure 9. In Figure 9(a), when the bock sets on the left side, the maximum deformation of welds 1,2 , and 3 can reach $0.35 \mu \mathrm{m}$, while the deformations of welds 4 and 5 are only $0.1 \mu \mathrm{m}$. In Figure 9(b), when the block sets at the right side, the maximum deformation of welds 1,2 , and 3 can reach $0.35 \mu \mathrm{m}$ and the deformation of weld 4 is $0.15 \mu \mathrm{m}$; however, weld 5 does not show periodicity. From the results in Figure 9, we find that the periodic loading pressure causes weak deformation of the welds, especially for weld 5 .

3.5. 4000 s Long Cycle Loading Test. Furthermore, to explore the effect of long-term periodic loading on the weld, we monitored the above four sets of experiments for up to $4000 \mathrm{~s}$. The pressure waveforms applied by the test bench are illustrated in Figure 6. Here, we also conduct four sets of trials: (1) right side eccentric loading of the top beam on the high position; (2) right side eccentric loading of the top beam on the low position; (3) left side eccentric loading of the top beam on the high position; (4) left side eccentric loading of the top beam on the low position.

The comparison of (1) and (2) experimental results is shown in Figure 10. We can tell that, in the high-position experiment of the right eccentric load within $4000 \mathrm{~s}$, there is almost no cumulative deformation of the five welds over time. At the same time, in the low-position experiment of the right eccentric load, only the baseline of weld 2 has slowly shifted over time, and the other welds have not changed significantly.

Meanwhile, the comparison of (3) and (4) experimental results is shown in Figure 11. We can find that, in the highposition experiment of the left eccentric load, within $4000 \mathrm{~s}$, welds 3 and 5 depict slight cumulative deformation over time; especially the baseline of weld 5 varies from $-0.1 \mu \mathrm{m}$ to $+0.1 \mu \mathrm{m}$. On the other side, in the low-position experiment of the left eccentric load, welds 1, 4, and 5 present significant cumulative deformation; the biggest shift of the baseline appears in weld 4 , which varies from $-0.1 \mu \mathrm{m}$ to $+0.3 \mu \mathrm{m}$. Besides, in the dash line area, we find a jump appearing in five welds almost simultaneously. Since the weld maintains the original creep law after the jump, it is almost impossible for this jump to be caused by weak cracks in the weld. Here, we think that the reverse four-bar linkage structure has changed to another balanced force state, a more stable state under long-term load. 


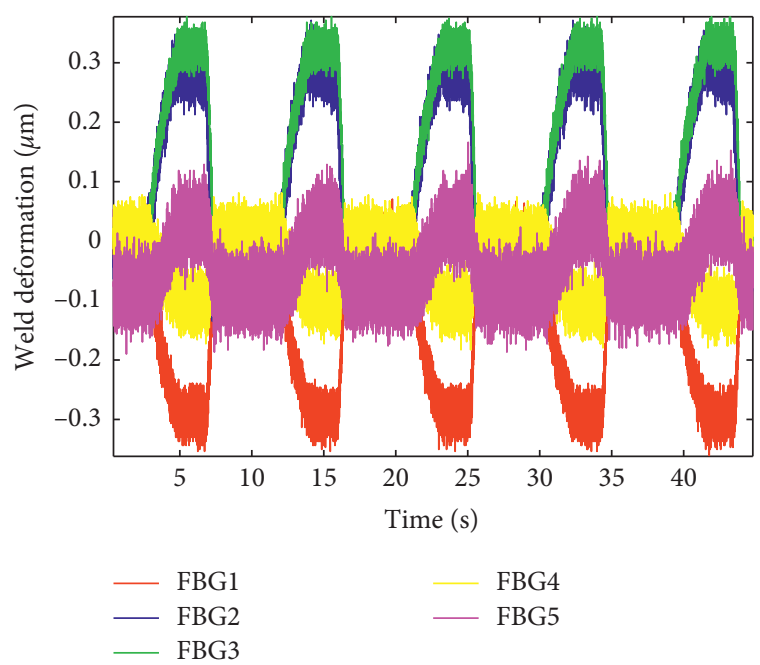

(a)

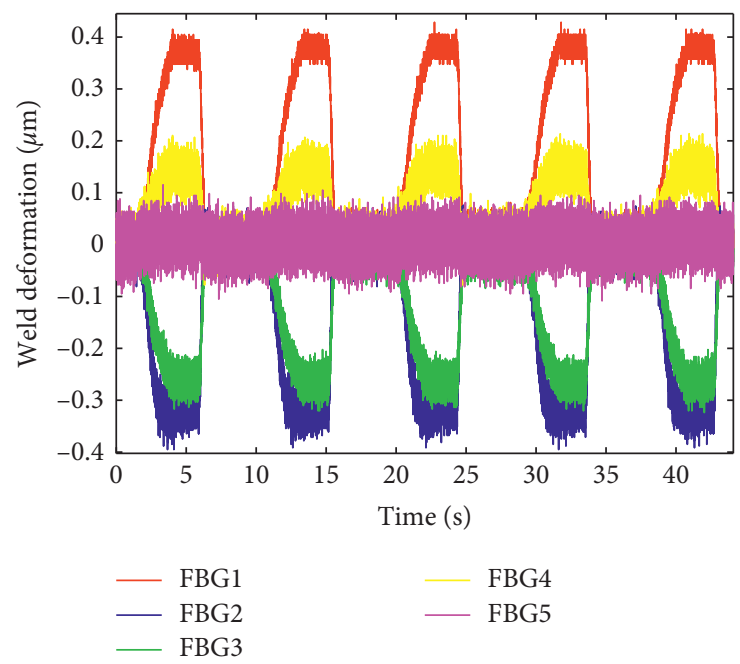

(b)

Figure 9: Cycle loading test with the top beam at a low position. (a) The block on the left side. (b) The block on the right side.
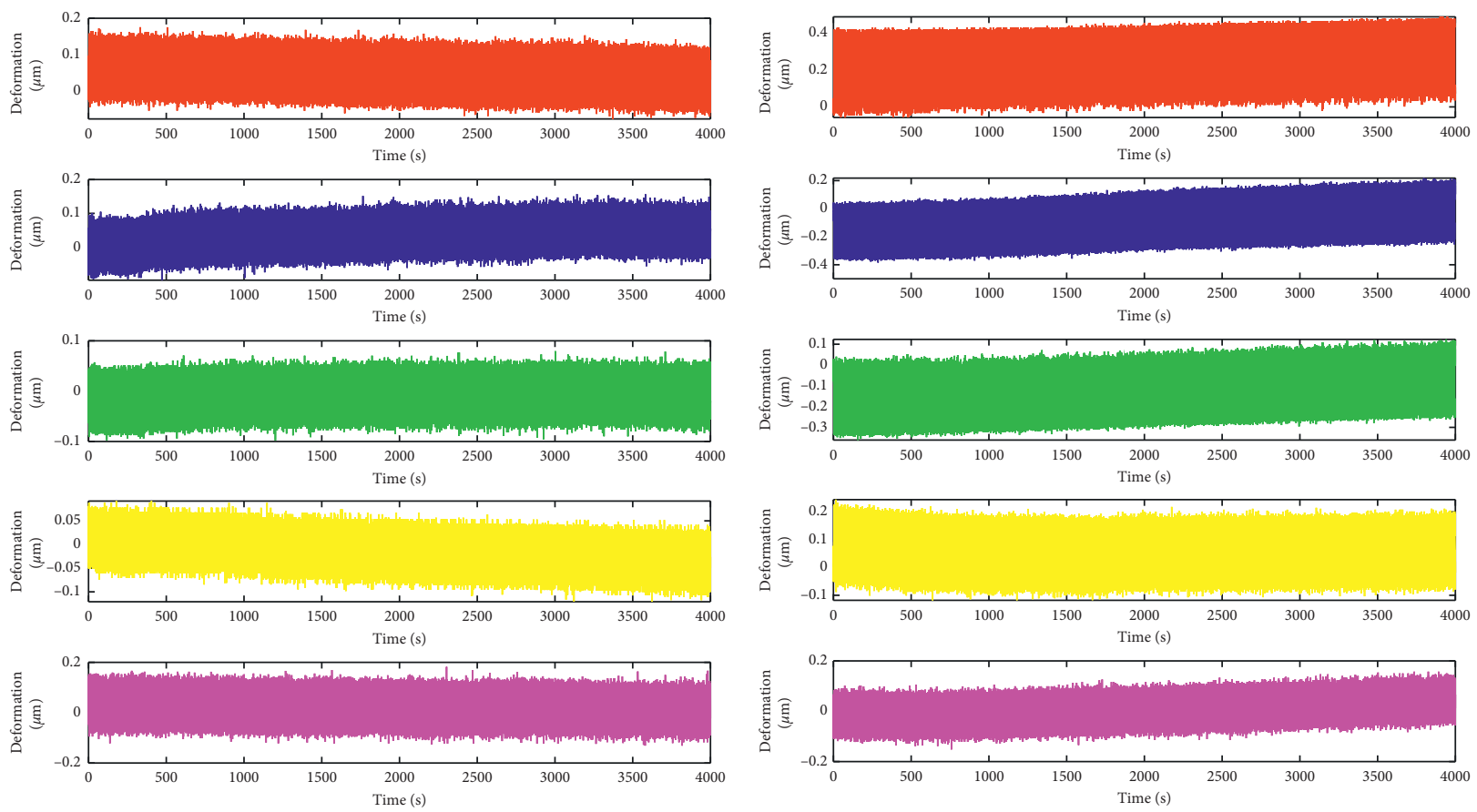

(a)

(b)

FIGURE 10: $4000 \mathrm{~s}$ cycle loading test with the block on the right side. (a) On the top position. (b) On the low position.

\section{Discussion}

As early as 1900, Barczak pointed out that the design of hydraulic supports should minimize stress concentration [28]. Although electrical strain gauges have long been used for monitoring structural changes, they sometimes lack the durability and integrity necessary to provide accurate, actionable information over extended periods. FBG-based optical fiber strain gauges offer a variety of advantages over electrical strain gauges.
In the National Coal Mine Support Equipment Quality Supervision and Inspection Center, the fiber grating sensing technology is used to realize the online monitoring of welds in the hydraulic support loading experiment. The results are reliable, proving that it is accurate enough to measure welding deformation by FBG sensors. Although the current hydraulic support test standards do not propose requirements for real-time monitoring of welds, whether the current Chinese test standard or the European test standard regards manual inspection of the degree of weld cracking as 

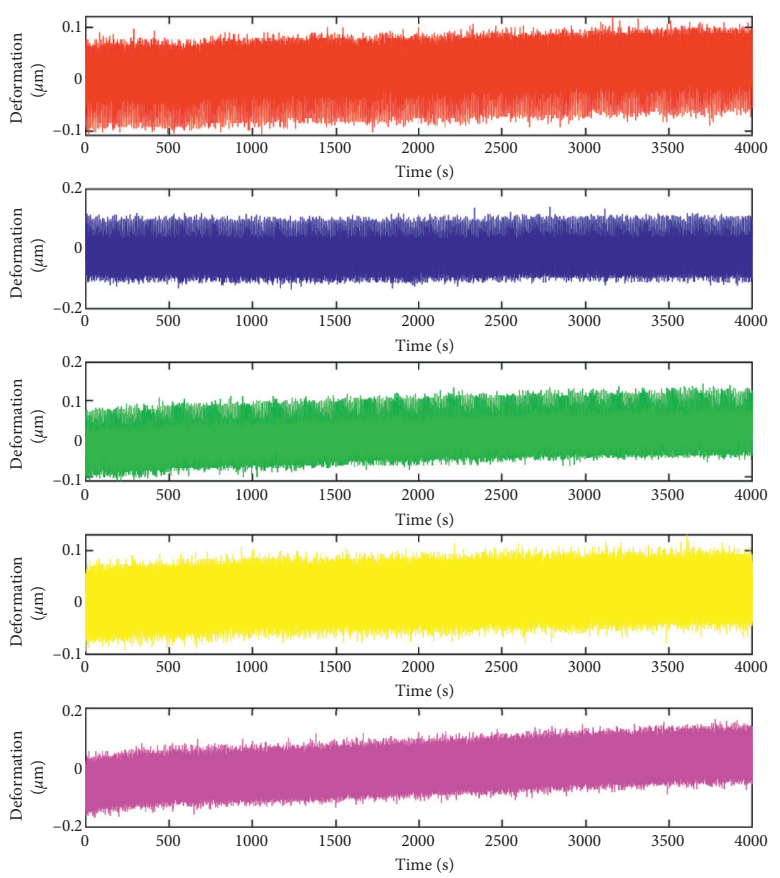

(a)
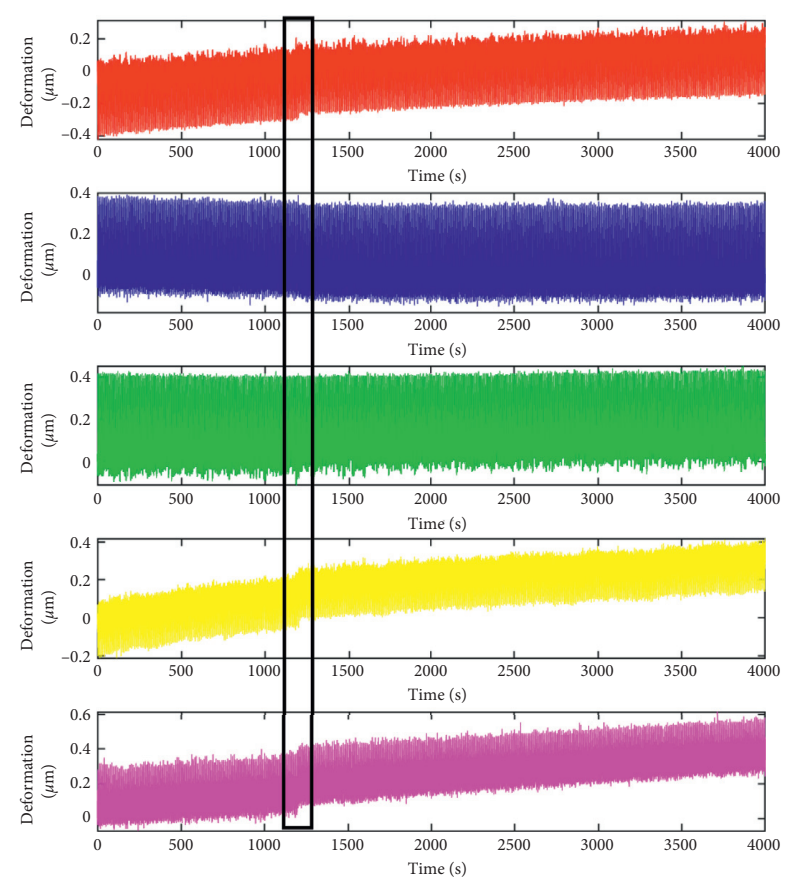

(b)

FIGURE 11: 4000 s cycle loading test with the block on the left side. (a) On the top position. (b) On the low position.

an indispensable item. Our research provides a feasible solution for real-time monitoring of hydraulic support welds, whether in the testing phase or the practical phase.

Due to the complex structure of the hydraulic support and the various types of welds, in the following research, the development of weld measuring sensors suitable for various planes and angles is an urgent problem to be solved.

In the cycle test, the welds present a baseline shift along with the cyclic load. It indicates the hydraulic support changes from one stable state to another stable state. This experimental result shows that welding seam monitoring can provide necessary feedback information for the cooperative support of hydraulic supports.

\section{Conclusions}

In this paper, a commercial FBG sensor is adopted to measure the welding deformations of a reverse four-bar hydraulic support. A synchronized measurement system is designed, which contains a hydraulic pressure measurement unit and an optical fiber data acquisition unit.

To reveal the welding deformation of the reverse fourbar linkage in the eccentric loading experiment, the strength test and the cycle life test of the top coal caving reverse fourlink support with four typical eccentric load were conducted, respectively, in the National Coal Mine Support Equipment Quality Supervision and Inspection Center.

According to the results, we can conclude the following:

(1) FBG sensor is accurate enough to measure welding deformation; measurement resolution reaches $0.1 \mu \mathrm{m}$
(2) In the high and low loading test of the reverse fourbar linkage, the force distribution is not the same; the welding deformation caused by the change of the top beam position is greater than the welding deformation caused by the loading test

(4) Continuous long-term loading will cause the weld to show baseline shift or even jump to another stable state

\section{Data Availability}

Researchers can obtain the data from the corresponding author via dusy6509@163.com.

\section{Disclosure}

This paper is already published in the preprint given at https://www.researchsquare.com/article/rs-607237/v1.

\section{Conflicts of Interest}

The authors declare that they have no conflicts of interest.

\section{Acknowledgments}

The authors would like to thank Junhui Wang for his advice and help about the 3D model of hydraulic support. This research was funded by the National Natural Science Foundation of China (Grant nos. 5207415, 551804158, and 51974159), Tiandi Technology Co., Ltd., Technology Innovation Fund (Grant nos. KJ-2021-KCMS-05 and 2020-TDZD005), and Key R\&D Program of Shandong Province (Grant no. 2019SDZY04). 


\section{References}

[1] J. Niu, "Study on automatic and intelligent following control system of hydraulic powered support in fully-mechanized coal mining face," International Journal of Coal Science \& Technology, vol. 43, no. 12, pp. 85-91, 2015.

[2] X. Fang, M. Liang, X. Xing, G. Xue, and M. Ma, "Development of hydraulic support pressure gauge based on FBG and its performance test," Caikuang yu Anquan Gongcheng Xuebao/ Journal of Mining and Safety Engineering, vol. 35, no. 5, pp. 945-952, 2018.

[3] Z. Cheng, L.-H. Li, and Y.-N. Zhang, "Laboratory investigation of the mechanical properties of coal-rock combined body," Bulletin of Engineering Geology and the Environment, vol. 79, no. 4, pp. 1947-1958, 2020.

[4] J. Wang, B. Yu, H. Kang et al., "Key technologies and equipment for a fully mechanized top-coal caving operation with a large mining height at ultra-thick coal seams," International Journal of Coal Science \& Technology, vol. 2, no. 2, pp. 97-161, 2015.

[5] J. Lou, F. Gao, J. Yang et al., "Characteristics of evolution of mining-induced stress field in the longwall panel: insights from physical modeling," International Journal of Coal Science \& Technology, vol. 24, 2021.

[6] X. Zhao, F. Li, Y. Liu, and Y. Fan, "Fatigue behavior of a boxtype welded structure of hydraulic support used in coal mine," Materials, vol. 8, no. 10, pp. 6609-6622, 2015.

[7] H. Junqing Liu and J. Liu, "The structure statics analysis and transient dynamics analysis of hydraulic support," in Proceeding of the 2011 International Conference on Electric Information and Control Engineering, pp. 895-898, Wuhan, China, April 2011.

[8] C. Fu Fang, X. Meng, Q. Hu et al., "TANDEM and GMAW twin wire welding of Q690 steel used in hydraulic support," Journal of Iron and Steel Research, vol. 19, no. 5, pp. 79-85, 2012.

[9] T. M. Barczak, "Examining longwall shield failures from an engineering design and operational perspective," in Proceedings of the New Technology for Coal Mine Roof Support, Pittsburgh, PA, USA, 2000.

[10] D.-Z. Kong, Z.-B. Cheng, and S.-S. Zheng, "Study on the failure mechanism and stability control measures in a largecutting-height coal mining face with a deep-buried seam," Bulletin of Engineering Geology and the Environment, vol. 78, no. 8, pp. 6143-6157, 2019.

[11] G. F. Pereira, L. P. Mikkelsen, and M. McGugan, "Crack detection in fibre reinforced plastic structures using embedded fibre Bragg grating sensors: theory, model development and experimental validation," PLoS One, vol. 10, no. 10, pp. e0141495-38, 2015.

[12] M. Liang, X. Fang, H. Bai, X. Xing, and G. Wu, "Application of temperature compensation fiber Bragg grating pressure sensor for bolting quality monitoring," Meitan Xuebao/ Journal China Coal Soc.vol. 42, no. 11, pp. 2826-2833, 2017.

[13] S. Pamukcu, L. Cheng, and M. Pervizpour, "Introduction and overview of underground sensing for sustainable response," Underground Sensing, Academic Press, Cambridge, MA, USA, pp. 1-42, 2018.

[14] Y. P. Wu, B. S. Hu, and P. S. Xie, "A new experimental system for quantifying the multidimensional loads on an on-site hydraulic support in steeply dipping seam mining," Experimental Techniques, vol. 43, no. 5, pp. 571-585, 2019.

[15] M. Liang, X. Fang, S. Li, G. Wu, M. Ma, and Y. Zhang, "A fiber Bragg grating tilt sensor for posture monitoring of hydraulic supports in coal mine working face," Measurement, vol. 138, pp. 305-313, 2019.

[16] Z. Ma and X. Chen, "Fiber Bragg gratings sensors for aircraft wing shape measurement: recent applications and technical analysis," Sensors, vol. 19, no. 1, p. 55, 2019.

[17] J. G. Burnett, P. M. Blanchard, and A. H. Greenaway, "Optical fibre-based vectoral shape sensor," Strain, vol. 36, no. 3, pp. 127-133, 2000.

[18] E. Ilbeygi, M. Jahanbakhshian, M. Arshadi Pirlar, and R. Karimzadeh, "Magnetic field sensor based on plasmonic fiber optics coupled with smartphone," Optics \& Laser Technology, vol. 140, Article ID 107065, 2021.

[19] R. Somma, C. Troise, L. Zeni et al., "Long-term monitoring with fiber optics distributed temperature sensing at campi flegrei: the campi flegrei deep drilling project," Sensors, vol. 19, no. 5, Article ID 1009, 2019.

[20] M. Nishiyama and K. Watanabe, "Frequency characteristics of hetero-core fiber optics sensor for mechanical vibration," Sensors and Actuators A: Physical, vol. 209, pp. 154-160, 2014.

[21] H. Yuting and H. Yuting, "Research progress of dynamic measurement technology based on Brillouin optical timedomain analysis," Laser \& Optoelectronics Progress, vol. 55, no. 10, Article ID 100004, 2018.

[22] V. G. M. Annamdas, "Review on developments in fiber optical sensors and applications," International Journal of Materials Engineering, vol. 1, no. 1, pp. 1-16, 2012.

[23] S. Kang, G. Dong, J. Qiu, and Z. Yang, “(INVITED) Hybrid glass optical fibers-novel fiber materials for optoelectronic application," Optical Materials X, vol. 6, Article ID 100051, 2020.

[24] E. K. Rotich Kipnoo, G. M. Isoe, D. K. Boiyo et al., "All optical polarization-based and DSP-Assisted distributed fiber sensor for earth mass movements caused by environmental factors," Optik, vol. 206, Article ID 163691, 2020.

[25] N. Sabri, S. A. Aljunid, M. S. Salim, R. B. Ahmad, and R. Kamaruddin, "Toward optical sensors: review and applications," Journal of Physics: Conference Series, vol. 423, Article ID 012064, 2013.

[26] K. O. Hill, Y. Fujii, D. C. Johnson, and B. S. Kawasaki, "Photosensitivity in optical fiber waveguides: application to reflection filter fabrication," Applied Physics Letters, vol. 32, no. 10 , pp. 647-649, 1978.

[27] C. Campanella, A. Cuccovillo, C. Campanella, A. Yurt, and V. Passaro, "Fibre Bragg grating based strain sensors: review of technology and applications," Sensors, vol. 18, no. 9, Article ID 3115, 2018.

[28] T. M. Barczak, "Design considerations for the next generation of longwall shields," in Proceedings of the Longwall USA Conference and Exhibit, Pittsburgh, PA, USA, June 1900. 